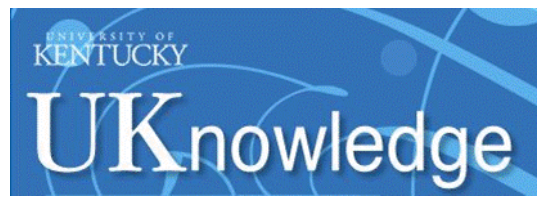

University of Kentucky

UKnowledge

\title{
Synthesis of Graphene Oxide Membranes and Their Behavior in Water and Isopropanol
}

\author{
Ashish Aher \\ University of Kentucky, ashish.aher@uky.edu \\ Yuguang Cai \\ University of Kentucky, YuguangCai@uky.edu \\ Mainak Majumder \\ Monash University, Australia \\ Dibakar Bhattacharyya \\ University of Kentucky, db@uky.edu
}

Follow this and additional works at: https://uknowledge.uky.edu/cme_facpub

Part of the Chemical Engineering Commons, and the Materials Science and Engineering Commons Right click to open a feedback form in a new tab to let us know how this document benefits you.

\section{Repository Citation}

Aher, Ashish; Cai, Yuguang; Majumder, Mainak; and Bhattacharyya, Dibakar, "Synthesis of Graphene Oxide Membranes and Their Behavior in Water and Isopropanol" (2017). Chemical and Materials Engineering Faculty Publications. 60.

https://uknowledge.uky.edu/cme_facpub/60

This Article is brought to you for free and open access by the Chemical and Materials Engineering at UKnowledge. It has been accepted for inclusion in Chemical and Materials Engineering Faculty Publications by an authorized administrator of UKnowledge. For more information, please contact UKnowledge@lsv.uky.edu. 
Synthesis of Graphene Oxide Membranes and Their Behavior in Water and Isopropanol

Digital Object Identifier (DOI)

https://doi.org/10.1016/j.carbon.2017.01.086

Notes/Citation Information

Published in Carbon, v. 116, p. 145-153.

(C) 2017 Published by Elsevier Ltd.

This manuscript version is made available under the CC-BY-NC-ND 4.0 license https://creativecommons.org/licenses/by-nc-nd/4.0/.

The document available for download is the author's post-peer-review final draft of the article. 


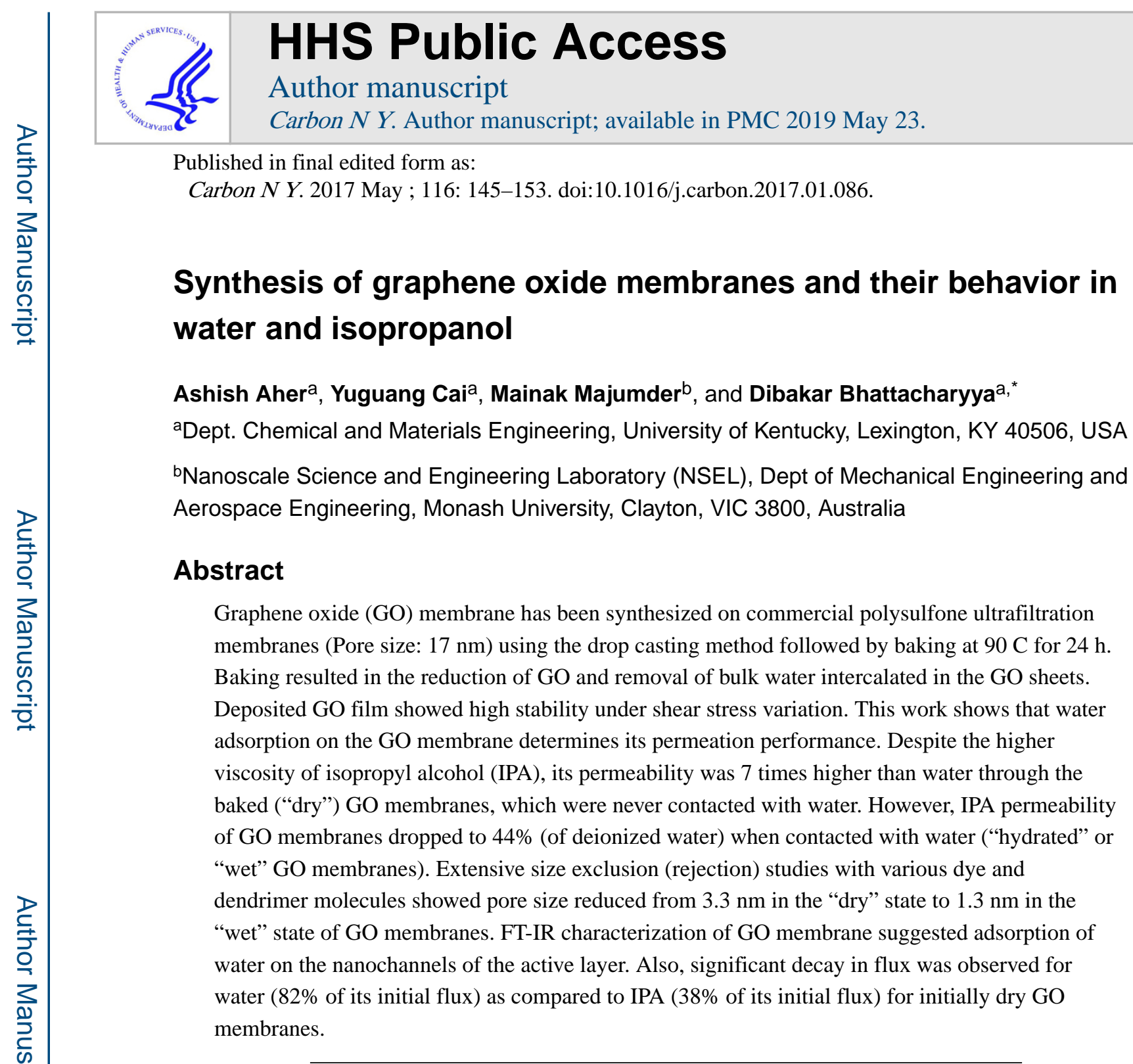

\section{Introduction}

Graphene-based materials have shown immense potentials for energy storage, metal free catalyst for fuel cells and advanced oxidation, along with the separations ranging from gas phase to water based systems [1-7]. Incorporation of Graphene Oxide (GO) on membrane surface or in the polymer matrix has demonstrated improved membrane properties, such as water permeance, anti-fouling and antimicrobial, solvent resistance, thermal and mechanical stability [8,9]. GO membranes have the capabilities to separate small organic molecules, divalent ions and gas phase separations. Thermal and solvent resistance of GO membranes enable them to work in certain cases, such as solvent based separations and fluids at elevated temperature, where application of polymeric membranes are limited due to thermal stability and solubility of polymer in solvent [10]. Simulation and experimental studies have

\footnotetext{
*Corresponding author: db@uky.edu (D. Bhattacharyya).

Appendix A. Supplementary data

Supplementary data related to this article can be found at http://dx.doi.org/10.1016/j.carbon.2017.01.086.
} 
demonstrated faster transport of water through monolayer of graphene, thus identifying the capabilities for more energy efficient separations [11-14]. However, the complexities involved in the synthesis of monolayer graphene membranes limited their practical realization. GO membranes on the other hand, can be easily fabricated on porous substrates by stacking multiple GO sheets, using the process of drop casting, vacuum filtration, and doctor blade, giving it an edge over monolayer graphene and other polymeric nanofiltration membranes [15-18]. The nanoscale dimension of the corridor for flow of fluid in GO membranes results in the slip of fluids at the interface, leading to a higher permeation rate than the predictions from the Hagen poiseuille equation [14,19,20]. Fast water transport along with the other aspects such as, ease of fabrication, separations on nanoscale (size), mechanical, thermal and solvent resistance make GO membranes a promising candidate for nanofiltration (NF) and have attracted attention of membrane community.

Graphene oxide is a two-dimensional nanomaterial, with the domains of $\mathrm{sp}^{2}$ hybridized carbon atoms arranged in a honeycomb structure decorated with domains of oxygen containing functionalities such as carboxyl, carbonyl, epoxy and hydroxyl attached to the $\mathrm{sp}^{3}$ carbon, on the basal plane. $\pi-\pi$ interactions of $\mathrm{sp}^{2}$ hybridized domains and hydrogen bonding through some of the oxygen containing functionalities gives it structural integrity, holding it in a laminar structure [21]. The GO membrane has a complex micro-structure consisting of channels between two GO sheets, inter-edge spaces, and wrinkles. Several molecular dynamic studies have investigated the transport mechanism of water through this complex microstructure. Studies indicate that transport of water is fast through the $\mathrm{sp}^{2}$ domains of GO, but limited by slower water transport in the $\mathrm{sp}^{3}$ domains [14]. It is also speculated that wide channels formed at wrinkles and inter-edge spaces are the major route for transport of water through the GO membranes. An interesting experimental demonstration by Gao's group showed narrowing of wrinkles on the GO membrane decreasing water flux with time at a constant pressure suggesting the importance of wrinkles in the transport of water [22]. As such, the study of GO membranes is still an emerging field and research to understand the atomic structure, transport mechanism, and separation mechanism is in progress [23-29].

The permeability of these membranes has shown different responses to the operating conditions compared to polymeric membranes. XRD studies have shown an increase in interlayer distance from $7.7 \AA$ to $12.09 \AA$ of GO when exposed to humid air suggesting hydration of GO membranes [20]. Any change in dimensions of the nanochannels would result in dramatically different rates of transport of fluids through the $\mathrm{GO}$ membranes. For example, Huang et al. noted the decline in water flux for GO membranes with increasing ionic strength using $\mathrm{NaCl}[30]$. Declining water flux was reported likely due to the screening of negative charge on the GO surface, resulting in less repulsion force between the GO sheets reducing the interlayer spacing. Pressure normalized flux for these membranes also reduced with increasing operating pressure, suggesting the narrowing of nanochannels under pressure. Furthermore, interactions of solvents with GO and their role in determining the permeability through GO membranes is also critical for solvent based applications [31]. Shi et al. observed a decrease in permeation of water while increasing oxidation extent of the GO, likely due to a higher degree of hydrogen bonding [32]. Water can form a stable adsorbates on the GO surface which has been observed to narrow the capillaries for flow of 
the fluids. This led to improved selectivity of GO membranes for gas phase separations $[3,33]$. Thermodynamic simulations performed by Korobov et al. suggest the different extent of intercalation of various solvent molecules in GO nanochannels [34]. Due to these differences in interactions, it may not be possible to predict the performance of GO membranes with organic solvents from their performance with aqueous solutions.

In this study, GO membranes were fabricated using the drop cast technique on commercial polysulfone ultrafiltration membranes. GO membranes were characterized by Fourier transform infrared spectroscopy (FTIR), Scanning electron microscopy (SEM), Contact angle, Raman spectroscopy and X-ray photoelectron spectroscopy (XPS) to establish the chemical state of GO in the membranes. Permeation and rejection performance of the GO membranes was measured for IPA and water as solvents. Our findings suggest that water adsorption on the GO surface is a critical factor that controls the flux and sieving effect of the GO membrane. For GO membranes, the previous history of contact with water or highly hydrophilic molecules is a major factor for their performance.

\section{Experimental}

\subsection{Materials}

Aqueous dispersion of Graphene Oxide (4 mg/ml) was purchased from Graphenea, Inc. PS35 (ultrafiltration membrane) and Dow NF270 (nanofiltration membrane) was supplied by Nanostone water Co. and Dow Flimtech, respectively. Reagent grade isopropanol, magnesium sulfate, ferricyanide $\left(\left[\mathrm{Fe}(\mathrm{CN})_{6}\right]^{3-}\right)$, rodamine B labeled polyethylene glycol with molecular weight of $5000 \mathrm{~g} / \mathrm{mol}$, FITC labeled polyethylene glycol with molecular weight $2000 \mathrm{~g} / \mathrm{mol}$, Tris(4-carbazoyl-9-ylphenyl) amine and humic acid were purchased from Sigma-Aldrich. All reagents were used as received. Water used at all stages of the experiments was purified (final resistivity $<18.2 \mathrm{M} \Omega$, TOC $<1 \mathrm{ppb}$ ) using a Purelab flex water purifier obtained from ELGA Lab water.

\subsection{Preparation of GO-PS 35 membranes using the drop-cast method}

GO membranes were fabricated using aqueous GO suspension $(4 \mathrm{mg} / \mathrm{ml})$ on commercial ultrafiltration membrane PS35. PS35 has a $30 \mu \mathrm{m}$ thick polysulfone layer having a mean pore size of $17 \mathrm{~nm}$ on a $150 \mu \mathrm{m}$ thick polyester support. Before using, the PS35 films $(10 \times$ $10 \mathrm{~cm}^{2}$ ) were first rinsed with deionized water to remove residual glycerol on top of it. After drying in air, dropwise deposition of $0.2 \mathrm{mg} / \mathrm{L}$ GO suspension on the surface of PS35 was carried out to get a loading of $120 \mathrm{mg} / \mathrm{m}^{2}$. The PS35 membrane has some hydrophilicity due to the presence of additives (Polyvinylpyrrolidone), which helped in spreading of suspension and formed a thin film of GO on the PS35 surface. GO suspension deposited on PS35 membranes was dried in stagnant air. Air dried GO on the PS35 film was then incubated in the oven at $90{ }^{\circ} \mathrm{C}$ for $20 \mathrm{~h}$. GO coating on the PS35 film turned gray from light brown after incubation (Fig. S1). The composite film of GO and PS35 is referred as GO-PS35 membrane henceforth. 


\subsection{GO-PS35 membrane performance measurement}

The Sterlitech dead-end cell and the Sterlitech cross-flow cell were used to measure permeation of fluids and rejections of solutes. Dead-end filtration cell had an active filtration area of $13.2 \mathrm{~cm}^{2}$. Permeation rate measurements of fluid were carried out by monitoring the mass of permeate through the RS232 output of weighing scale at a sampling rate of $50 \mathrm{sec}$

${ }^{-1}$. Crossflow setup required a rectangular piece of membrane with an active filtration area of $20.6 \mathrm{~cm}^{2}$. Temperature of the working fluid was controlled at $24{ }^{\circ} \mathrm{C}$ in the crossflow setup. The flux was measured by recording the volume of permeate collected over $5 \mathrm{~min}$ at an interval of $2 \mathrm{~h}$ during the experiment. Flow diagram for the experimental setup is shown in Fig. S3.

\subsection{Rejection measurement}

The rejection $(\mathrm{R})$ is defined as follow,

$$
R=\left(1-\frac{C_{p e r}}{C_{f e e d}}\right) \times 100
$$

where $C_{p e r}$ is the concentration of the permeate and $C_{f e e d}$ is the concentration of the feed solution. The permeate and feed concentrations of the $\mathrm{K}_{3} \mathrm{Fe}(\mathrm{CN})_{6}$, Neutral Red and FITClabeled PEG solutions were measured with the UV-Vis spectrometer at $302 \mathrm{~nm}, 530 \mathrm{~nm}$, $525 \mathrm{~nm}$, respectively. During measurements, $250 \mathrm{ml}$ dye solutions were filled in the batch cell. The permeate concentration was sampled after passing $30 \mathrm{~mL}$ of dye solution through the GO membrane. Also, rejection tests were carried on three independently synthesized GO membranes and measurements were repeated three times on the same piece of membrane each time to account for the adsorption and experimental error. To reduce the influence of the concentration polarization (possible cake layer formation) on rejection data, the feed solutions were stirred at $300 \mathrm{rpm}$ using magnetic stirrer in the filtration cell to avoid buildup of the solute at the surface. The rejection of saturated solution of humic acid was measured by the total carbon content (TOC) using the Shimadzu TOC 5000 TOC analyzer.

\subsection{GO-PS35 membrane characterizations}

The samples were characterized with the scanning electron microscope (SEM) mode on the focused ion beam (FIB) Helios NanoLab 660. The membrane was first coated with a layer of Platinum for the better cross sectional cutting. Ga ion beam (FIB) was then employed to cut through the membrane, generating a cross-section. X-ray photoelectron spectroscopy (XPS) characterization was conducted using the Thermo Scientific Al K-Alpha X-ray Photoelectron Spectrometer with photon energy of $1486.6 \mathrm{eV}$. Each XPS spectrum was an average of five scans. Infrared spectra of GO membranes were obtained using the Agilent Cary 630 IR spectrometer. The spectra were acquired in the ATR mode at $8 \mathrm{~cm}^{-1}$ resolutions. The contact angle of water on GO membranes was determined by Rame-Hart manual contact angle goniometer (model 100) by the sessile drop technique. Contact angles were measured for three independently synthesized membranes at five different locations and an average values were reported. A Chromex Raman 2000 spectrograph (Bruker) was used with a laser source output at $533 \mathrm{~nm}$. X-ray diffraction patterns were obtained using 
SIEMENS D500 diffractometer with Al-Ka radiation $(\lambda=1.5418 \AA)$ at an accelerating voltage of $40 \mathrm{kV}$ and a current of $20 \mathrm{~mA}$.

\section{Result and discussion}

\subsection{Characterization GO-PS35 membrane}

Fig. 1 (a) shows the SEM image of the top surface for the GO-PS35 membrane. Flat surface with some wrinkles, can be seen for GO-PS35 membrane after baking. Fig. $1 \mathrm{~b}$ shows the cross-section image of the GO-PS35 membrane after baking. For the GO loading of 120 $\mathrm{mg} / \mathrm{m}^{2}$, the SEM image of the cross-section shows an average thickness of $48 \mathrm{~nm}$ of the GO layer which is consistent with the results published by Han et al. [20].

FTIR spectra of GO membranes was collected to understand the functionalities present on $\mathrm{GO}$ and water sorption in the membrane. The characteristic peaks of the GO were not observed on polysulphone support likely due to the significant interference of the supporting polysulphone in the analysis because of the high penetration depths of IR radiation (close to $1 \mu \mathrm{m}$ depending on the polymer and wavelength of the incident radiation) compared to GO layer thickness. Therefore, FT-IR characterization was carried out with free standing GO membranes. The FTIR spectra of freestanding GO membrane in air-dried state, after $90{ }^{\circ} \mathrm{C}$ baking, GO-PS35 after $90{ }^{\circ} \mathrm{C}$ baking and clean PS35 are shown in Fig. 2. In the IR spectra of $\mathrm{GO}$, the carboxylic group, the aromatic $\mathrm{C}=\mathrm{C}$ bond stretching and the bending of water, the $\mathrm{C}-\mathrm{O}$ epoxy bond stretching and the $\mathrm{C}-\mathrm{O}$ aliphatic bond stretching peaks are clearly visible, which is consistent with the literature [35-37]. For the IR spectra of the air-dried GO membrane and baked GO membrane, the main difference was observed in the water $(\mathrm{OH})$ stretching band in the range of $3000-3700 \mathrm{~cm}^{-1}$. Spectrum of air dried membrane showed a strong and broad water band, suggesting the presence of water molecules within GO membrane in liquid state, forming hydrogen-bonded network [38]. In contrast, the spectrum of baked GO membrane showed water $(\mathrm{OH})$ peaks as two branches between 3400 and 3700 $\mathrm{cm}^{-1}$, each branch containing a series of discrete peaks. Such characteristics indicate that the water molecules inside GO membrane exist in mobile state, and inter-molecular interactions are reported to be weak [39]. Overall, these two spectra of GO membranes demonstrated that the baking process removed the bulk liquid phase water inside the GO membrane. We compared the intensity of epoxy peaks at $1150 \mathrm{~cm}^{-1}$ with the peak of carboxylic group at $1750 \mathrm{~cm}^{-1}$ as an internal standard, since it has been reported to be stable at $100{ }^{\circ} \mathrm{C}[40,41]$. Increase in the intensity of the epoxy band was observed after baking the membrane. This can be explained by the dehydration reaction between the surface hydroxyl group, in which two hydroxyl groups are converted into epoxy group and a water molecule is released. We also measured contact angle of GO membranes to study the change in hydrophilicity of GO surface before and after baking. The contact angle increased from $36^{\circ}$ to $59^{\circ}$ indicating that membrane turned hydrophobic to some extent after baking. The increase in hydro-phobicity was possibly due to dehydration of hydroxyl groups, as observed in IR studies.

Raman spectroscopy was used to confirm if any partial reduction was occurring during baking. D (at $1350 \mathrm{~cm}^{-1}$ ) and $\mathrm{G}$ (at $1580 \mathrm{~cm}^{-1}$ ) bands are observed for carbonaceous material. $\mathrm{G}$ band (the $\mathrm{E} 2 \mathrm{~g}$ mode of $\mathrm{sp}^{2}$ carbon) is observed for all graphitic structures, whereas D band (symmetric A1g mode) are from the disorder induced vibrational mode. 
Relative intensities of $\mathrm{D}$ to $\mathrm{G}$ has been reported as an indication for reduction of graphene oxide [42]. We observed that the intensity ratio for D/G band increased after baking GOPS35 membranes as shown in Fig. 3, further indicating the reduction of graphene oxide membrane. A similar reduction of GO membrane was reported for $\mathrm{GO}$ treated at $200{ }^{\circ} \mathrm{C}$ [43].

XPS spectra of the surface were obtained to study surface chemical composition and bonding. Fig. 4 shows the XPS spectra of the GO-PS35 membrane before and after baking process. The wide survey spectrum (insert) shows the presence of carbon (at $284.7 \mathrm{eV}$ ) and oxygen (at $532.5 \mathrm{eV}$ ) from GO. The $\mathrm{C} 1 \mathrm{~s}$ peak of the carbon 1s emission was deconvoluted into three peaks corresponding to the carbon in the $\mathrm{C}-\mathrm{C}$ bonding state $(284.7 \mathrm{eV})$, the $\mathrm{C}-\mathrm{O}-$ $\mathrm{C}(286.4 \mathrm{eV})$ bonding state and the c6arbonyl/carboxylic bonding state $(288.6 \mathrm{eV})$, respectively [37,42]. We observed small reduction (28\%-24\%) of atomic \% oxygen after baking the GO membranes. The decrease in peak intensity at $286.4 \mathrm{eV}$ suggests some loss of C-O functionalities. FT-IR characterization (Fig. 2) also confirmed the presence of same characteristic groups. Yang et al. also reported extensive XPS data on the reduction of graphene oxide after heating GO in a controlled environment from $200{ }^{\circ} \mathrm{C}$ to $1000{ }^{\circ} \mathrm{C}$ [43]. In conclusion, our characterization of the $\mathrm{GO}$ membranes suggests the partial reduction of the GO after baking the membrane at $100{ }^{\circ} \mathrm{C}$ for $24 \mathrm{~h}$.

\subsection{Water permeability of the GO-PS35 membranes}

Permeability of the GO membranes is inversely proportional to the amount of GO deposited. However, a finite amount of GO is required to have a significant rejection for solute (Size > $1.3 \mathrm{~nm}$ ) depending on the method for synthesis of the GO membranes [16,20]. In our experiments, we used the GO loading of $120 \mathrm{mg} / \mathrm{m}^{2}$; the water permeability of the corresponding $48 \mathrm{~nm}$ thick GO membranes had an average value of $3.7 \mathrm{LMH} / \mathrm{bar}$ with a standard deviation of $2.4 \mathrm{LMH} / \mathrm{bar}$, which are in the same order of magnitude of GO membranes prepared by the filtering methods [20,33,44]. During the evaporation of thin film of the GO suspension, the "coffee ring" effect lead to the variation in thickness of the deposited GO layer over different parts of the membrane [45,46]. As a result, the GO-PS35 membranes formed by the drop-cast method showed some variations in GO membrane thickness, which lead to the variations in the permeability. Supporting PS35 platform also has some resistance for the flow of fluid. Baked PS35 membrane had a permeability of 137 LMH/bar whereas, baked GO-PS35 membrane had a permeability of 3.7 LMH/bar suggesting that GO deposited on porous substrates governed the final permeability of the membranes (SI, Sec. S4). Higher loading of GO $\left(120 \mathrm{mg} / \mathrm{m}^{2}\right)$ was deliberately chosen for the study to ensure better separation property of the GO membrane towards dyes.

\subsection{Performance stability of GO membrane under crossflow operation}

Shear stability of GO membranes in aqueous environment has been identified as one of the challenge limiting its commercial application [47]. Membrane surface typically experiences a shear stress exerted by the solvent (typically in the range of $0.25-4 \mathrm{~Pa}$ for water as the solvent) under crossflow conditions in membrane modules [48]. It is important to demonstrate the limits of shear stability of the synthesized GO film, as GO from the active layer is dispersible in water. We observed that baking at $90{ }^{\circ} \mathrm{C}$ for $20 \mathrm{~h}$, prevented GO flakes 
detaching from the PS35 supporting platform (SI, Sec. S3). To mimic the actual conditions for membrane applications, permeability and salt rejection of GO membrane was monitored in the crossflow setup for $20 \mathrm{~h}$, under an estimated shear stress of $1.7 \mathrm{~Pa}$, exerted by water (detailed calculation can be found in SI, Sec. S6). A constant permeability of $3.2 \mathrm{LMH} / \mathrm{bar}$ and a rejection of $21 \%$ for $1000 \mathrm{ppm} \mathrm{MgSO}_{4}$ were observed over $20 \mathrm{~h}$, as shown in Fig. 5. Insert in Fig. 5 shows the permeability of the membrane under varying shear stress conditions for GO-PS35 membrane. Stable water flux and rejection was observed over the course of experiment. A control study with the air dried GO-PS35 membrane showed a rapid increase in the permeability (to $178 \mathrm{LMH} / \mathrm{bar}$ within $20 \mathrm{~min}$ ), suggesting the loss of GO from the top surface.

GO is readily dispersible in water due to the presence of hydrophilic functionalities like carboxyl, epoxy and hydroxyl functionalities on the basal plane of the graphene oxide. The GO basal plane consists of hydrophobic domains containing $\mathrm{sp}^{2}$ hybridized carbon while the hydrophilic domain consisting of oxygen-containing functionality. On baking of the graphene oxide membranes, partial reduction of GO was observed. The $\pi-\pi$ interaction between the adjacent GO flakes in the stack is likely to have enhanced due to increase in the $\mathrm{sp}^{2}$ domain with the reduction of GO. Thus, giving integrity to the GO membrane under shear exerted by the solvent. In conclusion, we observed the stable performance of GO-PS35 membrane under crossflow conditions.

\subsection{Role of water sorption on GO in permeation of IPA}

Permeance of IPA through GO-PS35 membrane was monitored in "dry" and "wet" state of GO. First, we heated the Dead-end membrane cell at $120^{\circ} \mathrm{C}$ in the oven to remove residue water in the membrane cell. Then we filled the cell with ultrapure isopropanol for measurement. In this case, the permeability of isopropanol for the dry GO-PS35 membrane was 20.1 LMH/Bar. Next, the membrane cell was washed with DI water and permeability of 1.6 LMH/bar for IPA was observed (Fig. 6) Finally, we conducted a control test and measured the permeability of clean PS35 membrane in isopropanol. We obtained a permeability of $88 \mathrm{LMH} / \mathrm{Bar}$, which is smaller than the permeability for water (260 LMH/ Bar), but still significantly larger than the measured isopropanol permeability of GO-PS35 membrane. The data from control test demonstrated that the measured permeability of GOPS35 in isopropanol reflects the property of the GO membrane, rather than the permeability of underneath PS35 supporting platform.

A considerable drop in IPA flux was noticed when the GO membrane was contacted with water as shown in Fig. 6. Our IR spectroscopy on the GO membrane demonstrated when the baked GO membrane was contacted with water for $15 \mathrm{~min}$, its IR spectrum changed (Fig. 2) from the baked state to wet state. Therefore, based on the IR spectra of GO, we speculate that the flux decay of GO membrane is likely due to the slow hydration/adsorption of water on the surface of GO sheet [21]. To further test this hypothesis, we obtained the IR spectra of baked GO membrane and the IR spectra of the GO membrane soaked in isopropanol. Dry GO membrane soaked in isopropanol was placed in a stream of pure nitrogen for $4 \mathrm{~h}$ before acquiring the spectrum. We found that its spectrum is similar to that of the baked GO membrane, with no isopropanolspecific asymmetric $\mathrm{CH}_{3}$ stretching at $2960 \mathrm{~cm}^{-1}$ [49]. 
Hence, this IR study reveals that the isopropanol does not form a stable adsorbates on the GO sheet surface at room temperature. Recent works of Lai group also showed that the inter-layer distance for the isopropanol soaked GO membrane and the dry GO membrane are the same at room temperature indicating no isopropanol adsorption [33].

As we know, permeability is inversely proportional to the viscosity of the liquid at a given pressure. The viscosity of water and isopropanol is $0.895 \mathrm{cP}$ and $2.038 \mathrm{cP}$, respectively at $25^{\circ} \mathrm{C}[50,51]$. So for a given channel dimension, the flux for IPA should be lower than that of water. This is indeed the case for "wet" GO-PS35 membrane. The viscosity of water is $56 \%$ less than the viscosity of isopropanol. Our data also showed that the flux of isopropanol is $58 \%$ less than the flux of water (Fig. 6, Insert), which clearly indicates that the liquid viscosity accounts for the measured difference in water/isopropanol flux for wet GO-PS35 membrane. Observed high flux of IPA in "dry" GO in comparison with water flux (or IPA flux in "wet" state of GO membranes) could be explained by narrowing of effective pore size of the GO membranes (according to Hagen Poiseuille equation) when contacted with water because of the formation of the stable adsorbates layer. This further strengthens our hypothesis.

If our mechanism is correct, then we can infer that for isopropanol with water content, the stabilized flux would be the same as the anhydrous isopropanol passing through a "wet" GO-PS35 membrane. This inference is based on the fact that water molecules in isopropanol will adsorb on the GO channel surface, leading to the reduction of the effective pore size and a decrease in the isopropanol flux. To test this inference, we measured the flux of the isopropanol/water mixture with 5 and $25 \%$ mass of water and Fig. 7 shows the observed flux profile. We observed a significant decrease in the flux of mixture as compared to anhydrous IPA. From exponential decay model fitting of the plot, we can see that indeed the permeability decayed to $1.9 \mathrm{LMH} / \mathrm{Bar}$. At $10.34 \mathrm{Bar}$, its corresponding flux (cross) is plotted together with the isopropanol flux (diamond) of wet state GO-PS35 membrane at $10.34 \mathrm{Bar}$ in Fig. 6. The two symbols in the figure overlap, which indicates their permeabilities are similar. Change in flux with time for IPA-water mixture (75\%-25\%) is also shown in Fig. S9.

For further validation of the hypothesis, we measured IPA flux of the GO-PS35 membrane in the "dry" and "wet" state for three cycles. Initially, anhydrous IPA was passed through the membrane followed by water and again IPA. Flux was monitored for each pass in the cycle. After completion of the cycle, GO-PS35 membrane was dried by solvent exchange and baking. We observed similar behavior for the following cycles further validating the hypothesis as shown in Fig. 8. In summary, the permeability for water remains at a constant value, which is irrelevant to what solvents it had contacted. In contrast, the permeability of isopropanol for the GOPS35 membrane has two different values. For dry GO-PS35 membrane, the isopropanol permeability was $20.1 \mathrm{LMH} / \mathrm{Bar}$, it drops significantly if the membrane had been in contact with water.

\subsection{XRD analysis}

The $\mathrm{D}(001)$ is a direct measure of the interlayer spacing between the GO sheets. Intercalation of the solvent in the GO sheets can be evaluated by monitoring shifts in the 
(001) peak after soaking the GO membranes in solvents. We performed XRD analysis of the baked and air dried GO membranes in different solvent environments to study the effect on the channel width.

$\mathrm{D}(001)$ diffraction peaks of the GO membranes showed a decrease in interlayer spacing from $8.6 \AA$ (for air dried GO membranes) to $7.9 \AA$ (for baked GO membranes) after baking process (Fig. S10). The interlayer spacing of the GO sheets in the GO membranes is controlled by the attractive forces of the $\mathrm{sp} 2$ domains and repulsive forces of the negative carboxylate groups. The decrease in the interlayer spacing after baking is likely due to the enhanced interaction of the sp2 domains due to the partial reduction of GO. The baked GO membranes, when soaked in water and IPA, showed an interlayer spacing of $12.5 \AA$ and 8.1 $\AA$, respectively. Interlayer spacing increased by $4.6 \AA$ after soaking the membranes in water, suggesting intercalation of water molecules. The GO membranes soaked in IPA didn't show any significant increase in interlayer spacing and is consistent with the literature [33]. Interestingly, GO membrane which was initially soaked in water, retained an interlayer spacing of $12.5 \AA$ after soaking in IPA, suggesting IPA molecules are unable to displace the water molecules intercalated in the GO sheets.

As mentioned earlier (sec.1), transport of fluid through GO membranes occurs through the channels between GO sheets, inter-edge spacing and wider openings due to wrinkles [14]. During the process of drying, the GO membranes develop defects in the microstructure leading to the formation of wider corridors [52]. Formation of disordered structure of the GO laminates during synthesis by a similar approach of vacuum filtration, was recently shown by Akbari et al. [16]. Corridors formed from these defects offers less resistance to the flow and are suspected as a major pathway for transport of water [14]. Gao et al. demonstrated narrowing of these wider corridors (surface wrinkles) when an extensive amount of water is passed through the membrane [22].

According to Hagen Poiseuille equation, the flow of fluid between parallel surfaces is proportional to the third power of the channel spacing and is inversely proportional to the viscosity. Higher channel width was observed for GO membranes in contact with water as compared to the one in contact with IPA. The higher flux of IPA through dry GO membranes suggest interlayer channels are possibly not the primary route for transport of the solvents, and other pathways, such as surface wrinkles and inter-edge spaces, plays a vital role in the transport of solvent. Therefore, size exclusion studies were carried out using various dyes and dendrimers with an objective to measure the effective pore size for the flow of fluids in the dry and wet state of the GO membranes.

\subsection{Rejection of dyes: to quantify the effective pore size for "dry" and "wet" state of the GO membranes}

Rejections of a series of dye molecules in both aqueous solutions and isopropanol solutions was measured for the GO-PS35 membranes. The obtained rejections data are plotted in Fig. 9. For these dye molecules, the size of $\mathrm{Mg}^{2+}, \mathrm{Fe}(\mathrm{CN})_{6}^{3-}$ ion, Neutral red (NR), Rhodamine 6G (R6G) is $0.8 \mathrm{~nm}, 0.9 \mathrm{~nm}, 1.26 \mathrm{~nm}, 1.6 \mathrm{~nm}$, respectively [53-56]. The sizes of FITClabeled Polyethylene glycol (PEG2k-FITC, MW 2000) and Rhodamine B-labeled 
polyethylene glycol (PEG5k-RB, MW 5000) are measured by dynamic light scattering. Size corresponding to $90 \%$ rejection of the solute was defined as the pore size in our study. Fig. 9 shows reduction of effective pore size from $3.3 \mathrm{~nm}$ in dry state to $1.3 \mathrm{~nm}$ in wet state. For wet GO-PS35 membranes, effective pore size was still $\sim 1.3 \mathrm{~nm}$ when isopropanol was passed through the membrane. Rejection of Neutral red, TCTA and Bromophenyl blue for the wet state of the membrane using IPA as the solvent also showed an effective pore size of $1.3 \mathrm{~nm}$. Rejection of the solute by GO membranes can be influenced by the charge on the solute. Graphene oxide is negatively charged and rejection of the positively charged species will be lower as compared to the negatively charged species according to the Donnan exclusion principle. In our study, we used a series of molecules with different charge (Neutral: Neutral red, TCTA, PEG; Negative: $\left[\mathrm{Fe}(\mathrm{CN})_{6}\right]^{3-}$, Bromophenyl blue; Positive: $\mathrm{Mg}^{2+}$, Rhoda-mine 6G). We observed a negligible deviation of the solute rejection from the trend line irrespective of the charge on solute suggesting charge didn't significantly influence the rejection. The change in selectivity in dry and wet state serve as an additional reference for the observed change in permeability of the membrane. The rejection of NR is $84 \%$ in aqueous solution (and IPA for the wet state), whereas nearly $0 \%$ in isopropanol (dry state). For the same molecule, this decrease in rejection indicates the increase of effective pore size of the GO membranes. To the best of our knowledge, this behavior has not been quantified in the literature.

Based on our observations (flux profiles of IPA in dry and wet state of GO, XRD characterization, size exclusion study) and existing literature on transport of fluid through GO membrane, we propose that when GO membranes are contacted with water, wider openings from the defects are narrowed by the formation of stable water sorbates and collapse of microstructural defects, such as shrinking of surface wrinkles, reducing its effective pore size. When the anhydrous IPA is passed through the membrane, no stable sorption occurs due to the weaker hydrophilic interactions. Therefore, GO membranes have a wider corridor opening resulting in high permeability for anhydrous IPA in "dry" state. However, in the presence of moisture in IPA, water forms stable adsorbates on the GO sheets and heals the microstructural defects to a greater extent, reducing the effective pore size to $1.3 \mathrm{~nm}$ and lowering its permeability. We also observed a recovery in IPA flux to its initial high value after drying the GO membranes (Fig. 8), and IR spectra (Fig. 2) suggested the loss of bulk water from the GO laminates, which further supports our argument that the decrease in effective pore size and flux is closely associated with the presence of water in the GO laminates.

\subsection{Flux decay of GO membranes}

We observed that the flux of GO-PS35 membrane is time dependent and requires considerable time to reach steady state flux (Fig. 10). For comparison, the flux of a commercial Dow NF270 as a function of time is also plotted. The exponential decay model was employed for flux decay to calculate the final asymptotic flux for GO-PS35 membranes. The results also enabled us to make quantitative comparison for the final flux of IPA through GO-PS35 in different states. Constant pressure of 3.34 bar was employed for the analysis. The flux $J_{S o l}$ as a function of time was fitted as an exponential decay curve in form as, 


$$
J_{\text {sol }}(t)=A e^{-\frac{t}{t_{D}}}+J_{\text {sol_stabilized }}
$$

where $J_{s o l}(t)$ is the measure flux in a given time, $t$ is time, $t_{D}$ is the decay constant, $J_{\text {sol_stabilized }}$ is the flux corresponding to stabilized flux (asymptotic value), and $A$ is the preexponential factor, $\mathrm{A}+J_{\text {Sol_stabilized }}$ corresponding to the initial flux $\left(J_{\text {Sol }}(O)\right)$ of the membrane. For a membrane, when there is a rapid decrease in permeance, $t_{D}$ approaches zero; while there is a very slow decay, $t_{D}$ approaches infinity.

The decay in water flux through GO-PS35 membranes was very slow (high $t_{D}$ ), and the flux restored to the initial high value upon drying the membrane. Flux decay was observed to be dependent on pressure, with faster decay at higher transmembrane pressure as shown in Fig. S7 and is consistent with the literature [22]. A plot of the flux against the amount of water passed through the membrane at different pressures coincided fairly suggesting the decay is a function of the amount of solvent passed through the membrane (Fig. S7). It is also worth mentioning that the flux decay of the IPA-water mixture showed slower kinetics as compared to anhydrous IPA (Fig. S9). Slower kinetics of flux decay is likely due to the interactions of IPA with the hydrophilic functionalities on GO through hydrogen bonding and possibly shielding the initial interactions of these functionalities with water to some extent.

The results of the fitting are summarized in Table 1. The stabilized flux of GO-PS35 membrane in water is only $18 \%$ of its original flux, whereas the stabilized flux of GO-PS35 membrane in isopropanol retains $62 \%$ of its original flux. Of course, with charged polymeric NF membranes (such as, NF 270) one would expect very low IPA permeability. In this article, all flux and permeability values reported are the stabilized values $\left(J_{\text {sol_stabilized }}\right)$.

The declining pressure normalized water flux was observed reversible and is consistent with the results published by Huang et al. [30]. Although the flux of the commercial polymeric nano-filtration membrane (NF 270) also decreased when contacted with water, flux stabilized quickly (Fig. 10). Flux decay is commonly observed for the polymeric membranes, and is mostly due to the compression of the polymer under transmembrane pressure. However, for the GO-PS35 membranes, kinetics of the decay was relatively slower. If our hypothesis is true, slow decay of flux for the GO-PS35 membrane is likely due to the slow formation of water adsorbates on the graphene oxide flakes, resulting in the reduction of the effective pore size. Fig. 10 shows a representative flux decay curve of a GO-PS35 membrane.

In summary, water adsorption on GO sheet plays a very important role in the observed difference in water and isopropanol permeabilities. GO basal plane, defect sites and edges of the GO sheets have hydrophilic carboxylic, carbonyl, epoxy and hydroxyl groups. When water molecules pass through these sites, they interact with these groups through hydrogen bonding probably forming water adsorbates in the channels and defects resulting in the narrowing of effective pore size for flow. According to our IR characterization, isopropanol molecules did not adsorb on the GO surface at room temperature. When isopropanol was 
passed through a "dry" GO-PS35 membrane, its effective pore size was higher $(3.3 \mathrm{~nm})$, and the flux of isopropanol remained high in contrast to the observed behavior for commercial polymeric nanofiltration membranes. For a GO-PS35 membrane already contacted with water or working in an aqueous solution, the water adsorbate layer had been already formed on the GO channel surface. When isopropanol was passed through such GO-PS35 membrane, because of the lower adsorption energy, the isopropanol molecule couldn't displace the water molecules already adsorbed on the GO channel surface. Therefore, in this case, the membrane effective pore size retained the value of water $(1.3 \mathrm{~nm})$.

\section{Conclusion}

GO membranes were prepared on commercial PS35 supporting platform using the drop casting method. The resulting GO-PS35 membrane demonstrated good mechanical stability and can be used in isopropanol as well as aqueous solutions with a $\mathrm{pH}$ value between 2.2 and 11.5. Partial reduction of GO membrane occurred on baking the membrane at $90{ }^{\circ} \mathrm{C}$. Baked GO film stability was further verified in a cross flow cell and high stability was demonstrated through shear stress variation between 0.2 and $1.7 \mathrm{~Pa}$. We demonstrated that water adsorption has significant effect on the permeance of anhydrous IPA. Permeability of IPA (and possibly for other organic solvents) that have weaker adsorption energy on the GO sheet than water molecules depended on whether the GO-PS35 membranes were initially in the "wet" or "dry" state. IPA permeability for "dry" state GO membrane was higher than its permeability for "wet" state the GO-PS35 membranes. Furthermore, our findings indicated that trace amount of water would result in flux decay of IPA through the GO-PS35 membranes. Larger solvent corridor for "dry" state GO membranes was observed than for "wet" state GO membrane in size exclusion studies. Dye rejection test indicated that GOPS35 membranes had a size cutoff of $3.3 \mathrm{~nm}$ and $1.3 \mathrm{~nm}$ for "dry" and "wet" state of GO, respectively. Thus, our study quantifies the role of solvent on permeability and effective pore size of the GO membranes using water, IPA, and known size organic solutes.

\section{Supplementary Material}

Refer to Web version on PubMed Central for supplementary material.

\section{Acknowledgment}

This research was supported by NSF KY EPSCoR grant (Grant no: 1355438), NIH-NIEHS-SRC (Award number: P42ES007380), and by Australian Research Council (through an A ARC Linkage LP140100959 grant). The authors thank Nicolas J. Briot, Dr. Rupam Sharma, Syed Islam, Michael Detisch for their contributions. Authors also thank the Nanostone Water Co., Oceanside, CA for providing the full-scale size PS35 membrane.
Abbreviations:
NF
Nanofiltration
UF
ultrafiltration
GO
graphene oxide
NR
neutral red 
R6G Rhodamine 6G

\section{References}

[1]. Joshi R, Carbone P, Wang F-C, Kravets VG, Su Y, Grigorieva IV, Wu H, Geim AK, Nair RR, Precise and ultrafast molecular sieving through graphene oxide membranes, Science 343 (6172) (2014) 752-754. [PubMed: 24531966]

[2]. Li H, Song Z, Zhang X, Huang Y, Li S, Mao Y, Ploehn HJ, Bao Y, Yu M, Ultrathin, molecularsieving graphene oxide membranes for selective hydrogen separation, Science 342 (6154) (2013) 95-98. [PubMed: 24092739]

[3]. Kim HW, Yoon HW, Yoon S-M, Yoo BM, Ahn BK, Cho YH, Shin HJ, Yang H, Paik U, Kwon S, Selective gas transport through few-layered graphene and graphene oxide membranes, Science 342 (6154) (2013) 91-95. [PubMed: 24092738]

[4]. Sun P, Zhu M, Wang K, Zhong M, Wei J, Wu D, Xu Z, Zhu H, Selective ion penetration of graphene oxide membranes, Acs Nano 7 (1) (2013) 428-437. [PubMed: 23214493]

[5]. Mi B, Graphene oxide membranes for ionic and molecular sieving, Science 343 (6172) (2014) 740-742. [PubMed: 24531961]

[6]. Gao W, Graphene Oxide: Reduction Recipes, Spectroscopy, and Applications, Springer International Publishing, 2015.

[7]. Zhu Y, Murali S, Cai W, Li X, Suk JW, Potts JR, Ruoff RS, Graphene and graphene oxide: synthesis, properties, and applications, Adv. Mater 22 (35) (2010) 3906-3924. [PubMed: 20706983]

[8]. Zhao C, Xu X, Chen J, Yang F, Effect of graphene oxide concentration on the morphologies and antifouling properties of PVDF ultrafiltration membranes, J. Environ. Chem. Eng 1 (3) (2013) 349-354.

[9]. Bao C, Guo Y, Song L, Hu Y, Poly (vinyl alcohol) nanocomposites based on graphene and graphite oxide: a comparative investigation of property and mechanism, J. Mater. Chem 21 (36) (2011) $13942-13950$.

[10]. Li GF, Wang X, Tao L, Li YS, Quan KC, Wei Y, Chi LF, Yuan QP, Cross-linked graphene membrane for high-performance organics separation of emulsions, J. Membr. Sci 495 (2015) 439-444.

[11]. Suk ME, Aluru N, Water transport through ultrathin graphene, J. Phys. Chem. Lett 1 (10) (2010) 1590-1594.

[12]. Cohen-Tanugi D, Grossman JC, Water desalination across nanoporous graphene, Nano Lett 12 (7) (2012) 3602-3608. [PubMed: 22668008]

[13]. O’Hern SC, Boutilier MS, Idrobo J-C, Song Y, Kong J, Laoui T, Atieh M, Karnik R, Selective ionic transport through tunable subnanometer pores in single-layer graphene membranes, Nano Lett 14 (3) (2014) 1234-1241. [PubMed: 24490698]

[14]. Wei N, Peng X, Xu Z, Understanding water permeation in graphene oxide membranes, ACS Appl. Mater. interfaces 6 (8) (2014) 5877-5883. [PubMed: 24669772]

[15]. Joshi R, Alwarappan S, Yoshimura M, Sahajwalla V, Nishina Y, Graphene oxide: the new membrane material, Appl. Mater. Today 1 (1) (2015) 1-12.

[16]. Akbari A, Sheath P, Martin ST, Shinde DB, Shaibani M, Banerjee PC, Tkacz R, Bhattacharyya D, Majumder M, Large-area graphene-based nano-filtration membranes by shear alignment of discotic nematic liquid crystals of graphene oxide, Nat. Commun 7 (2016).

[17]. Hu M, Mi BX, Enabling graphene oxide nanosheets as water separation membranes, Environ. Sci. Technol 47 (8) (2013) 3715-3723. [PubMed: 23488812]

[18]. Goh K, Setiawan L, Wei L, Si R, Fane AG, Wang R, Chen Y, Graphene oxide as effective selective barriers on a hollow fiber membrane for water treatment process, J. Membr. Sci 474 (2015) 244-253.

[19]. Huang H, Song Z, Wei N, Shi L, Mao Y, Ying Y, Sun L, Xu Z, Peng X, Ultrafast viscous water flow through nanostrand-channelled graphene oxide membranes, Nat. Commun 4 (2013). 
[20]. Han Y, Xu Z, Gao C, Ultrathin graphene nanofiltration membrane for water purification, Adv. Funct. Mater 23 (29) (2013) 3693-3700.

[21]. Dreyer DR, Park S, Bielawski CW, Ruoff RS, The chemistry of graphene oxide, Chem. Soc. Rev 39 (1) (2010) 228-240. [PubMed: 20023850]

[22]. Wei Y, Zhang Y, Gao X, Yuan Y, Su B, Gao C, Declining flux and narrowing nanochannels under wrinkles of compacted graphene oxide nanofiltration membranes, Carbon 108 (2016) 568-575.

[23]. Jia X, Campos-Delgado J, Terrones M, Meunier V, Dresselhaus MS, Graphene edges: a review of their fabrication and characterization, Nanoscale 3 (1) (2011) 86-95. [PubMed: 21103548]

[24]. Rafiee J, Mi X, Gullapalli H, Thomas AV, Yavari F, Shi Y, Ajayan PM, Koratkar NA, Wetting transparency of graphene, Nat. Mater 11 (3) (2012) 217-222. [PubMed: 22266468]

[25]. Guo F, Kim F, Han TH, Shenoy VB, Huang J, Hurt RH, Hydration-responsive folding and unfolding in graphene oxide liquid crystal phases, Acs Nano 5 (10) (2011) 8019-8025. [PubMed: 21877716]

[26]. Pacilé D, Meyer J, Rodríguez AF, Papagno M, Gomez-Navarro C, Sundaram R, Burghard M, Kern K, Carbone C, Kaiser U, Electronic properties and atomic structure of graphene oxide membranes, Carbon 49 (3) (2011) 966-972.

[27]. Yeh C-N, Raidongia K, Shao J, Yang Q-H, Huang J, On the origin of the stability of graphene oxide membranes in water, Nat. Chem 7 (2) (2015) 166-170.

[28]. Compton OC, Nguyen ST, Graphene oxide, highly reduced graphene oxide, and graphene: versatile building blocks for carbon-based materials, Small 6 (6) (2010) 711-723. [PubMed: 20225186]

[29]. Gómez-Navarro C, Meyer JC, Sundaram RS, Chuvilin A, Kurasch S, Burghard M, Kern K, Kaiser U, Atomic structure of reduced graphene oxide, Nano Lett 10 (4) (2010) 1144-1148. [PubMed: 20199057]

[30]. Huang H, Mao Y, Ying Y, Liu Y, Sun L, Peng X, Salt concentration, pH and pressure controlled separation of small molecules through lamellar graphene oxide membranes, Chem. Commun 49 (53) (2013) 5963-5965.

[31]. Talyzin AV, Hausmaninger T, You S, Szabó T, The structure of graphene oxide membranes in liquid water, ethanol and water-ethanol mixtures, Nanoscale 6 (1) (2014) 272-281. [PubMed: 24189605]

[32]. Shi G, Meng Q, Zhao Z, Kuan H-C, Michelmore A, Ma J, Facile fabrication of graphene membranes with readily tunable structures, ACS Appl. Mater. interfaces 7 (25) (2015) 1374513757. [PubMed: 26029815]

[33]. Hung W-S, An Q-F, De Guzman M, Lin H-Y, Huang S-H, Liu W-R, Hu C-C, Lee K-R, Lai J-Y, Pressure-assisted self-assembly technique for fabricating composite membranes consisting of highly ordered selective laminate layers of amphiphilic graphene oxide, Carbon 68 (2014) 670677.

[34]. Korobov MV, Talyzin AV, Rebrikova AT, Shilayeva EA, Avramenko NV, Gagarin AN, Ferapontov NB, Sorption of polar organic solvents and water by graphite oxide: thermodynamic approach, Carbon 102 (2016) 297-303.

[35]. Zhang Y, Zhang S, Chung TS, Nanometric graphene oxide framework membranes with enhanced heavy metal removal via nanofiltration, Environ. Sci. Technol 49 (16) (2015) 10235-10242. [PubMed: 26197200]

[36]. Jeong HK, Lee YP, Jin MH, Kim ES, Bae JJ, Lee YH, Thermal stability of graphite oxide, Chem. Phys. Lett 470 (4-6) (2009) 255-258.

[37]. Wang X, Song L, Yang H, Xing W, Kandola B, Hua Y, Simultaneous reduction and surface functionalization of graphene oxide with POSS for reducing fire hazards in epoxy composites, $\mathrm{J}$. Mater. Chem 22 (41) (2012) 22037-22043.

[38]. Benjamin I, Vibrational-spectrum of water at the liquid/vapor interface, Phys. Rev. Lett 73 (15) (1994) 2083-2086. [PubMed: 10056967]

[39]. Huisken F, Kaloudis M, Kulcke A, Infrared spectroscopy of small size-selected water clusters, J. Chem. Phys 104 (1) (1996) 17-25.

[40]. Gao X, Jang J, Nagase S, Hydrazine and thermal reduction of graphene oxide: reaction mechanisms, product structures, and reaction design, J. Phys. Chem. C 114 (2) (2009) 832-842. 
[41]. Zhou S, Bongiorno A, Origin of the chemical and kinetic stability of graphene oxide, Sci. Rep 3 (2013).

[42]. Zhang JL, Yang HJ, Shen GX, Cheng P, Zhang JY, Guo SW, Reduction of graphene oxide via Lascorbic acid, Chem. Commun 46 (7) (2010) 1112-1114.

[43]. Yang D, Velamakanni A, Bozoklu G, Park S, Stoller M, Piner RD, Stankovich S, Jung I, Field DA, Ventrice CA, Chemical analysis of graphene oxide films after heat and chemical treatments by X-ray photoelectron and Micro-Raman spectroscopy, Carbon 47 (1) (2009) 145-152.

[44]. Xu C, Cui A, Xu Y, Fu X, Graphene oxide-TiO2 composite filtration membranes and their potential application for water purification, Carbon 62 (2013) 465-471.

[45]. Deegan RD, Pattern formation in drying drops, Phys. Rev. E 61 (1) (2000) 475-485.

[46]. Yunker PJ, Still T, Lohr MA, Yodh AG, Suppression of the coffee-ring effect by shape-dependent capillary interactions, Nature 476 (7360) (2011) 308-311. [PubMed: 21850105]

[47]. Goh K, Karahan HE, Wei L, Bae T-H, Fane AG, Wang R, Chen Y, Carbon nanomaterials for advancing separation membranes: a strategic perspective, Carbon 109 (2016) 694-710.

[48]. Shakaib M, Hasani S, Mahmood M, CFD modeling for flow and mass transfer in spacerobstructed membrane feed channels, J. Membr. Sci 326 (2) (2009) 270-284.

[49]. Lu R, Gan W, Wu BH, Zhang Z, Guo Y, Wang HF, C-H stretching vibrations of methyl, methylene and methine groups at the vapor/alcohol $(n=1-8)$ interfaces, J. Phys. Chem. B 109 (29) (2005) 14118-14129. [PubMed: 16852773]

[50]. CRC Handbook of Chemistry and Physics, 91st ed., CRC Press Inc., Boca Raton, FL, 20102011.

[51]. The Water Encyclopedia. Geraghty \& Miller Ground-water Series, second ed., Lewis Pub, Chelsea MI, 1990.

[52]. Aba NFD, Chong JY, Wang B, Mattevi C, Li K, Graphene oxide membranes on ceramic hollow fibers-Microstructural stability and nanofiltration performance, J. Membr. Sci 484 (2015) 87-94.

[53]. Kielland J, Individual activity coefficients of ions in aqueous solutions, J. Am. Chem. Soc 59 (1937) 1675-1678.

[54]. Fornasiero F, Park HG, Holt JK, Stadermann M, Grigoropoulos CP, Noy A, Bakajin O, Ion exclusion by sub-2-nm carbon nanotube pores, in: Proceedings of the National Academy of Sciences of the United States of America, 105(45), 2008, pp. 17250-17255. [PubMed: 18539773]

[55]. Yuan X, Zhuo SP, Xing W, Cui HY, Dai XD, Liu XM, Yan ZF, Aqueous dye adsorption on ordered mesoporous carbons, J. Colloid Interface Sci 310 (1) (2007) 83-89. [PubMed: 17316672]

[56]. Tsunomori F, Ushiki H, Pore size effect on diffusion coefficient of rhodamine B in PNIPA gel, Phys. Lett. A 258 (2-3) (1999) 171-176. 

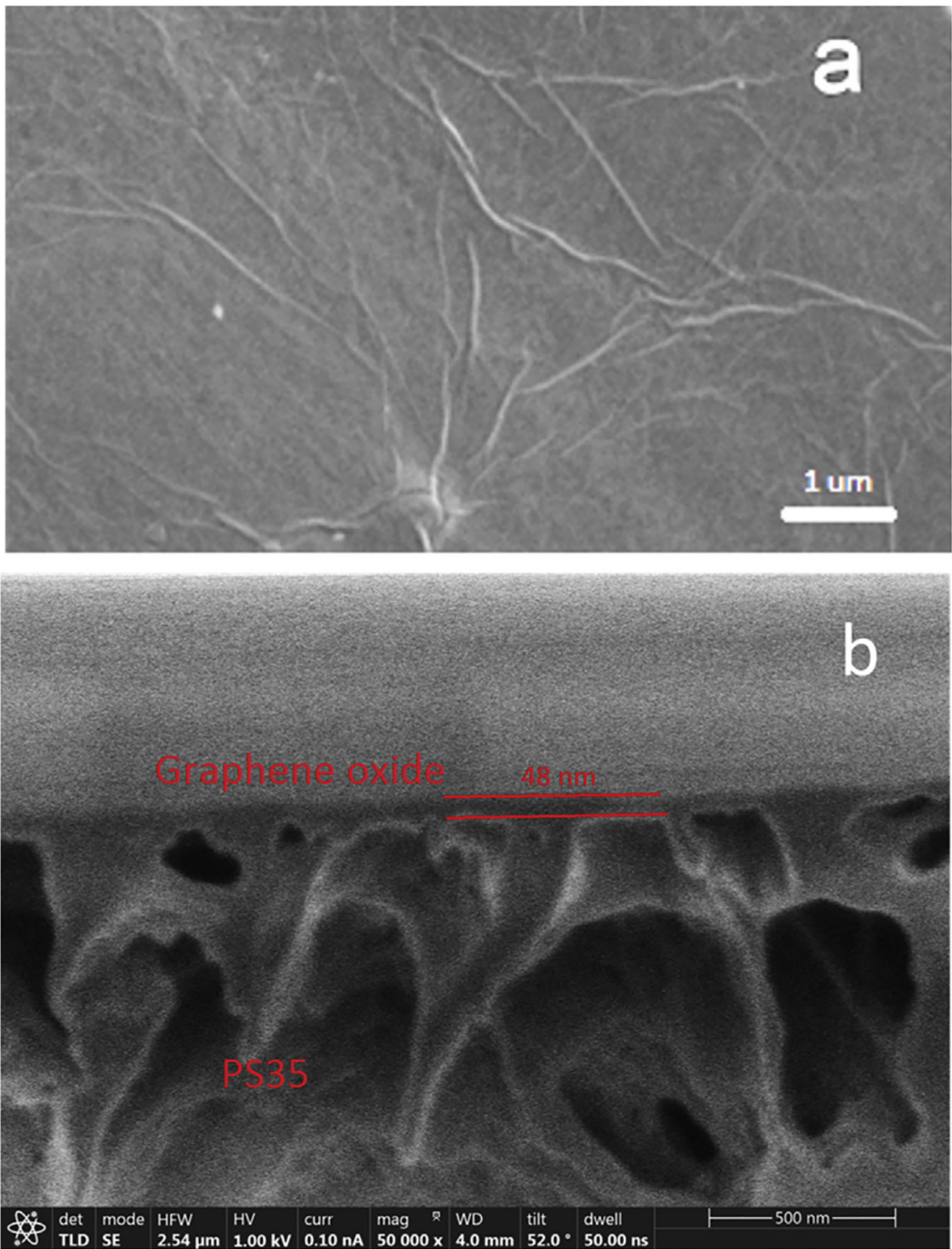

Fig. 1.

SEM images of GO-PS35 membrane. a) The top view, and b) The cross-section view of the GO-PS35 membrane. Image in b. shows the cross-section viewed from $52^{\circ}$ with respect to the GO membrane surface. (A colour version of this figure can be viewed online.) 


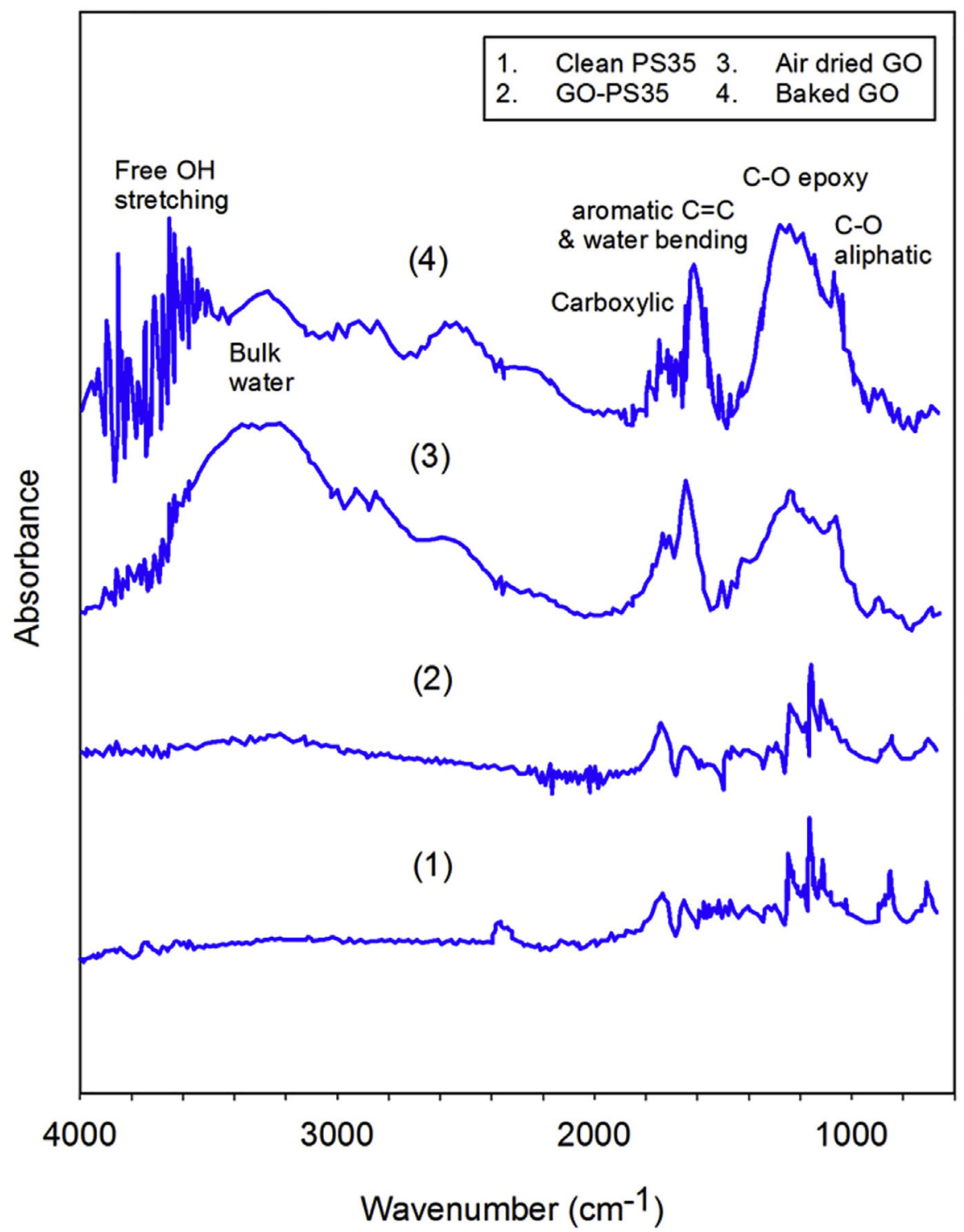

Fig. 2.

FTIR spectra of GO membranes. From top to bottom: baked GO membrane, air-dried GO membrane, GO-PS35 membrane, clean PS35 UF membrane, respectively. (A colour version of this figure can be viewed online.) 


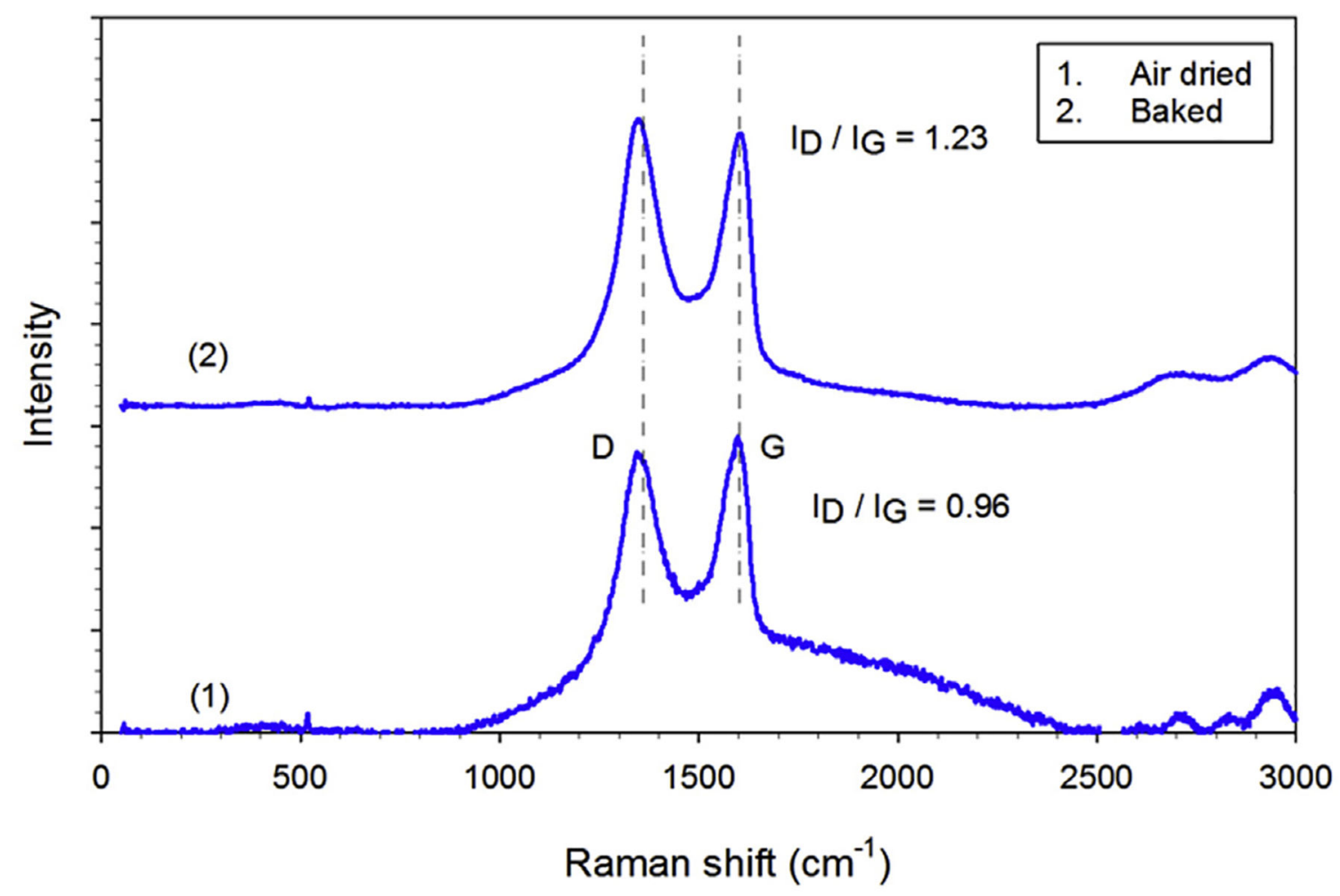

Fig. 3.

Raman spectra of air dried GO membrane (1) and baked GO membrane (2). (A colour version of this figure can be viewed online.) 
a)

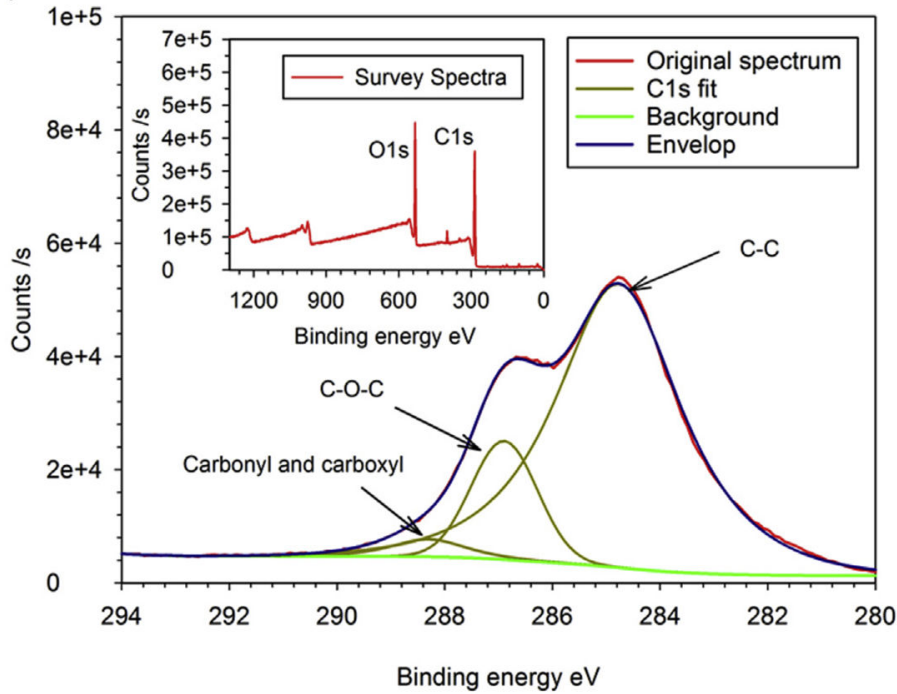

b)

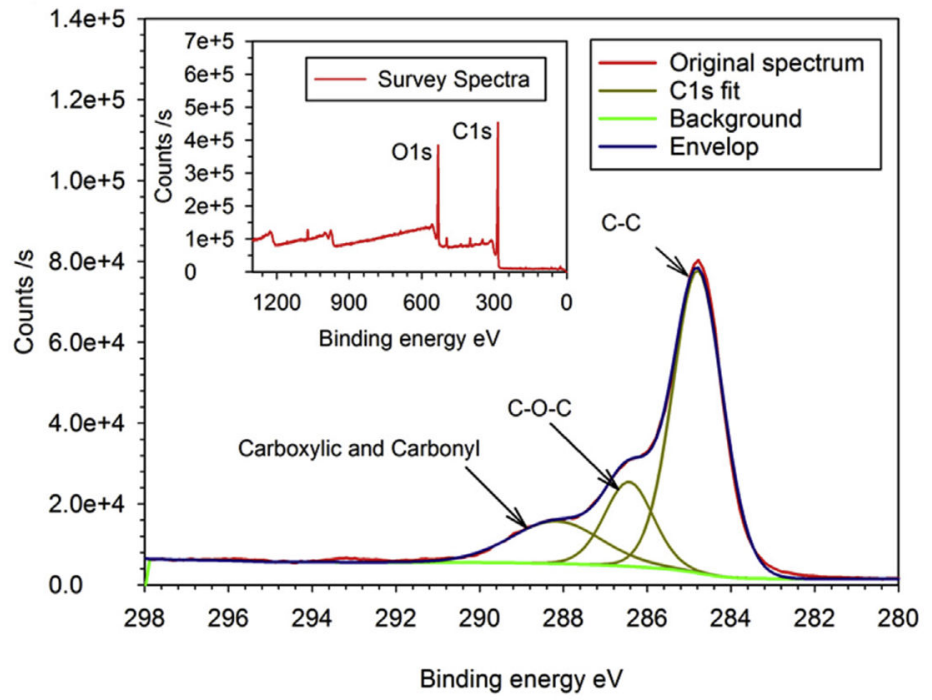

Fig. 4.

The XPS spectra of baked GO-PS35 membrane (a) air dried, (b) baked. (A colour version of this figure can be viewed online.) 


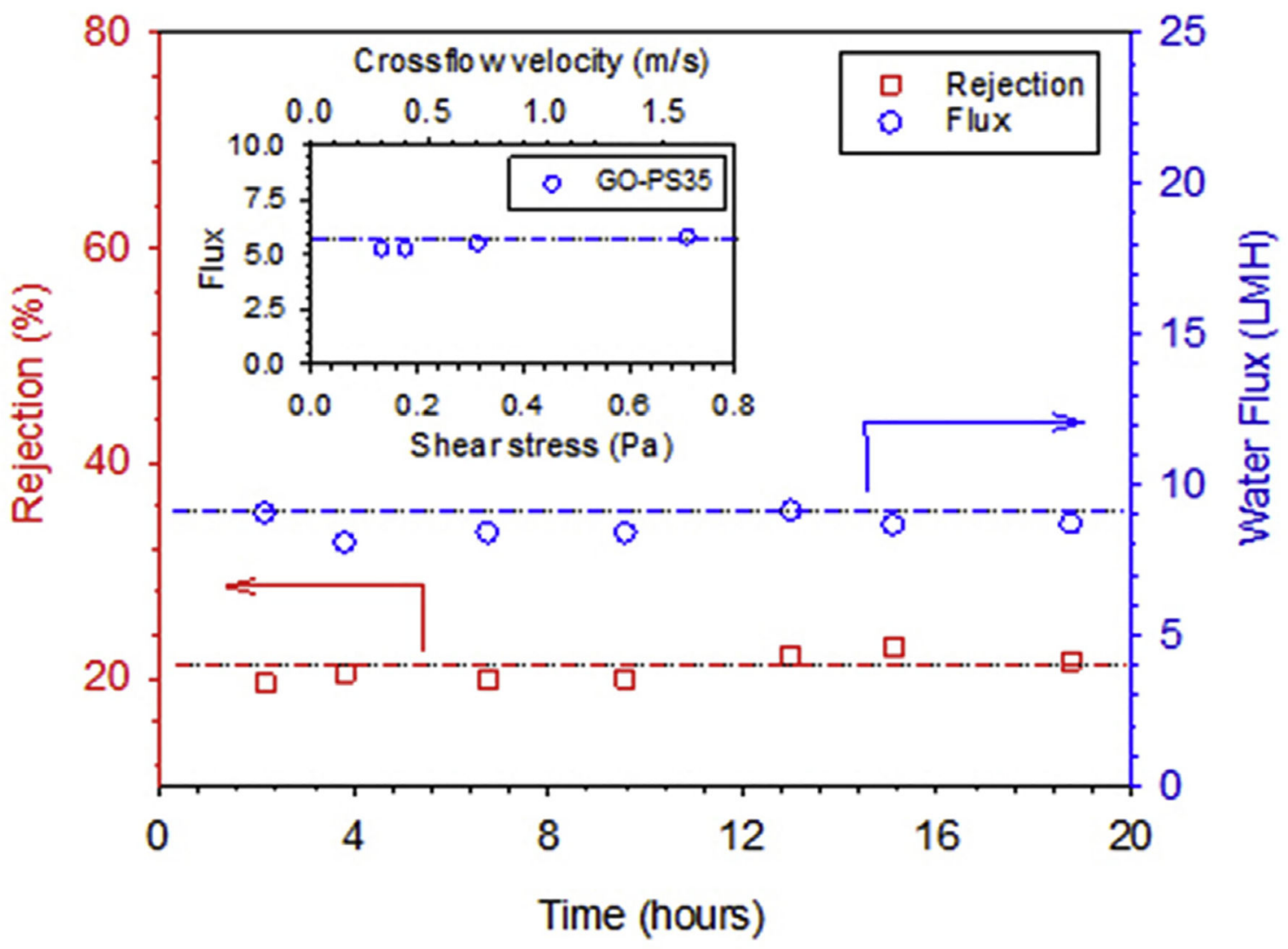

Fig. 5.

Stability analysis of GO-PS35 membrane in cross-flow setup. Operating conditions: Pressure: 2.75 bar, Mean temperature: $25{ }^{\circ} \mathrm{C}$, Cross-flow velocity: $3.8 \mathrm{~L} / \mathrm{min}$ (shear stress: 1.7 Pa), Salt: $\mathrm{MgSO}_{4} 1000$ ppm. Insert: DI water flux of GO-PS35 membrane under varying shear stress. (A colour version of this figure can be viewed online.) 


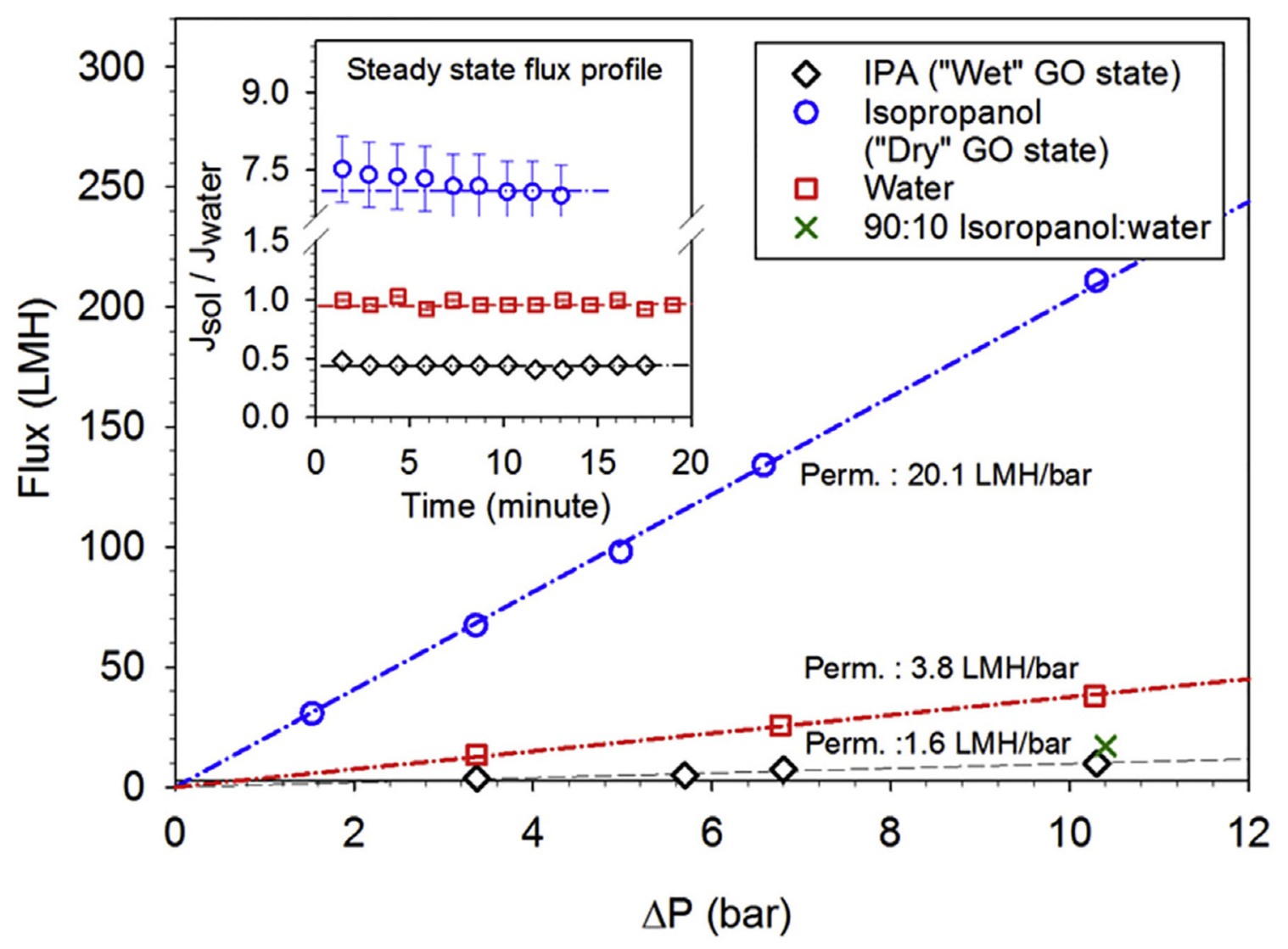

Fig. 6.

Flux as a function of driven pressure for GO-PS35 membrane in dry and wet states. Insert: Flux of IPA through "dry" and "wet" GO membranes, and water, normalized by steady state flux of water for three independently synthesized membranes. Standard deviations for normalized IPA flux through "dry" and "wet" GO membranes are 7\% and 8.5\% respectively. (A colour version of this figure can be viewed online.) 


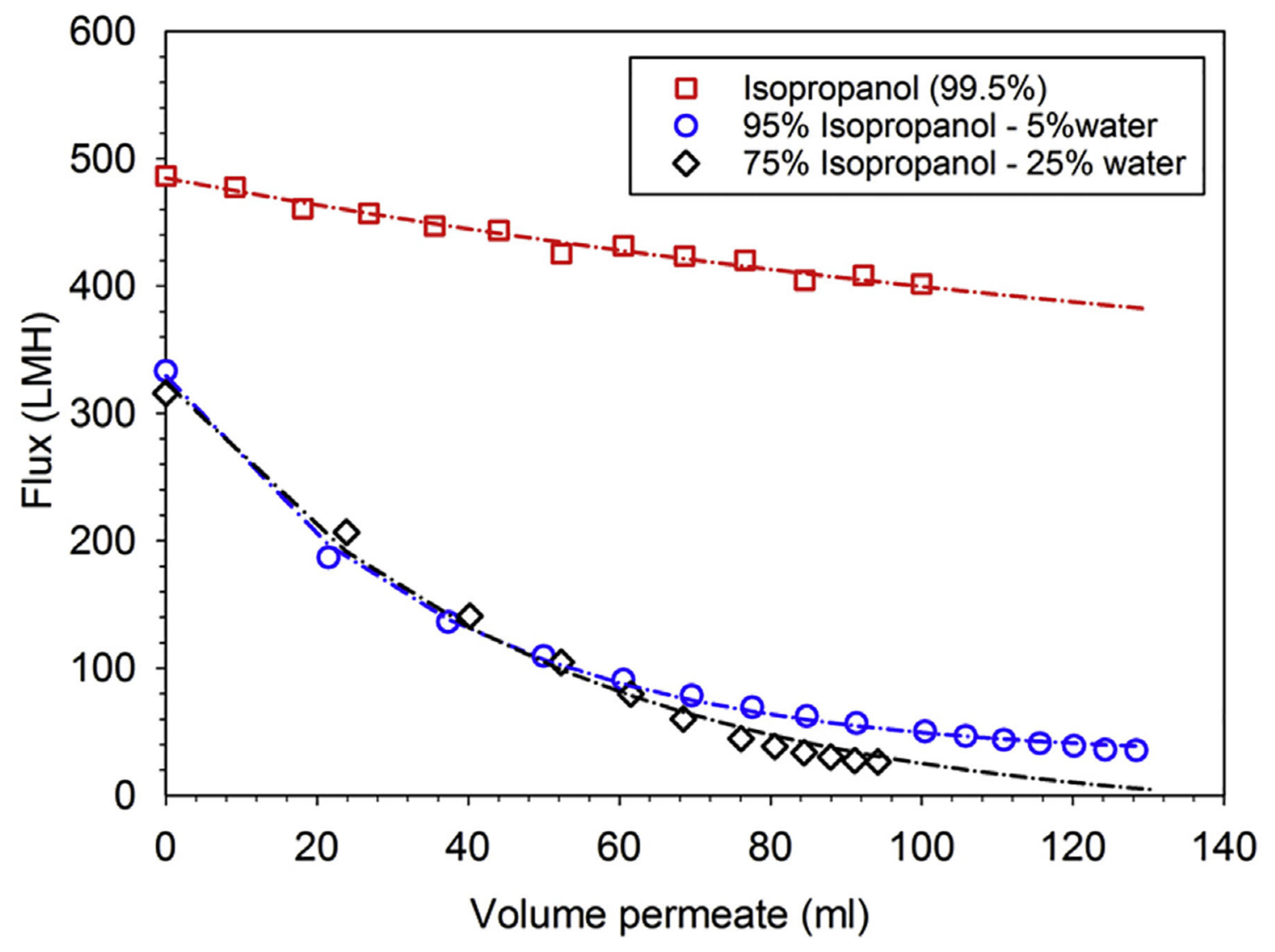

Fig. 7.

Flux of the mixture of Isopropanol-water through GO-PS35 membrane at 10.34 bar. (A colour version of this figure can be viewed online.) 


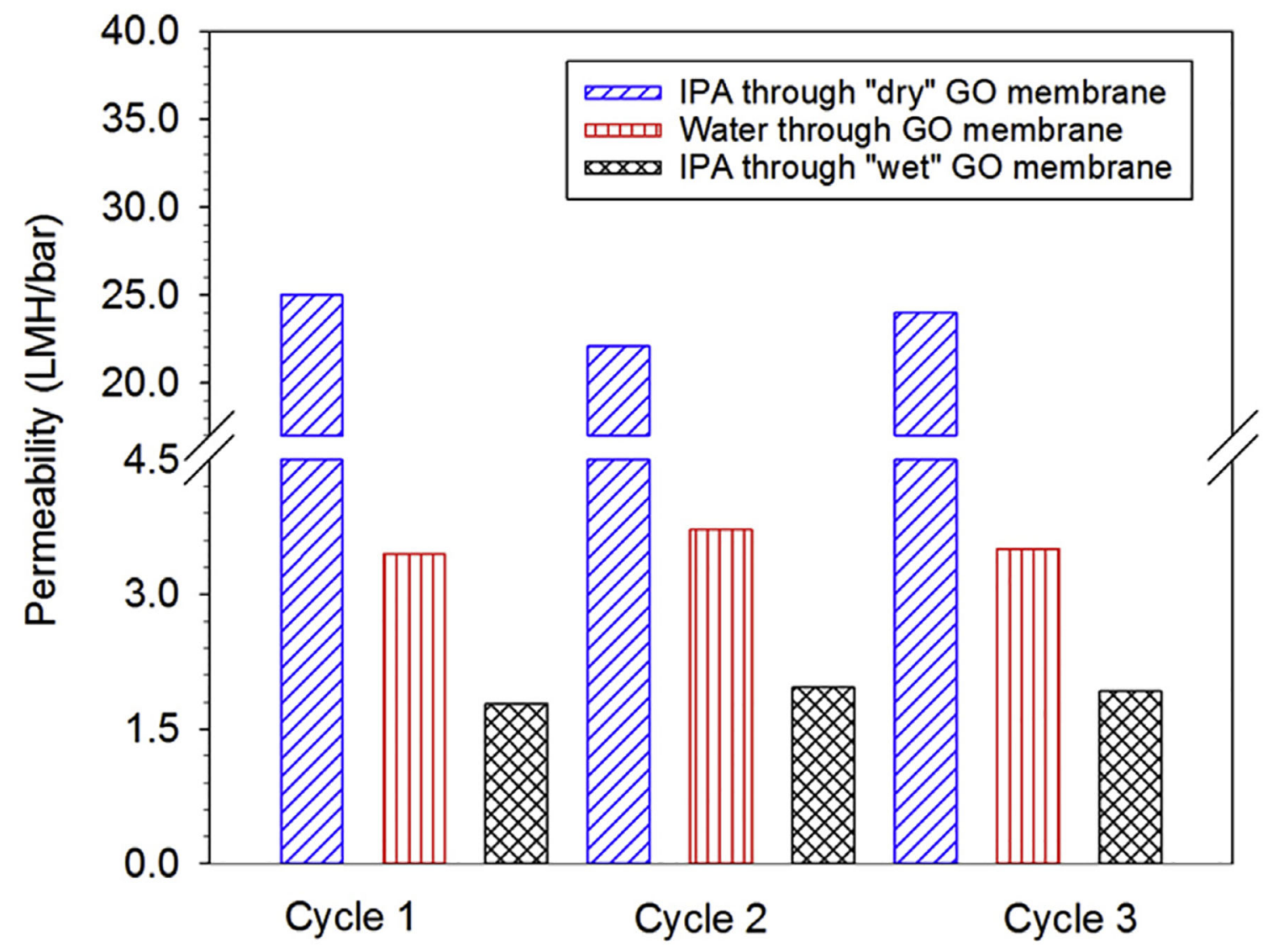

Fig. 8.

Steady state IPA permeability through "dry" and "wet" GO state, and water permeability for three repeated cycles showing the reversible nature of the GO membranes between "dry" and "wet" state. (A colour version of this figure can be viewed online.) 


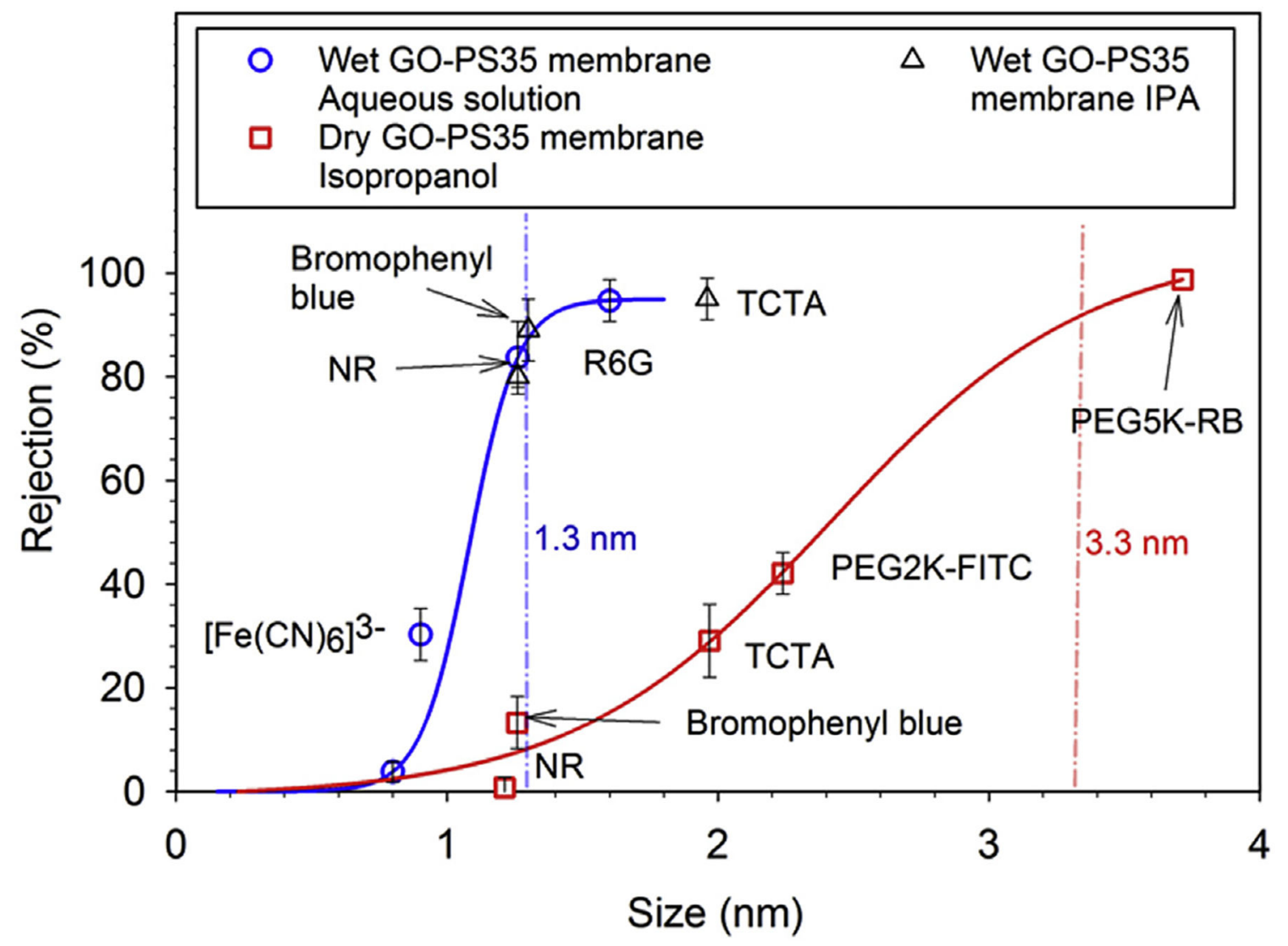

Fig. 9.

The rejection curves for aqueous solutions passing through, a) wet state GO-PS35 membrane, and b) isopropanol solutions passing through dry state PS35 membrane. Abbreviations in the plots: R6G: Rhodamine 6G, NR: Neutral Red, PEG5k-RB: Rhodamine B labeled-polyethylene glycol with molecular weight of $5000 \mathrm{~g} / \mathrm{mol}$. PEG2k-FITC: FITClabeled polyethylene glycol with molecular weight of $2000 \mathrm{~g} / \mathrm{mol}$. TCTA: Tris(4carbazoyl-9-ylphenyl)amine. The sizes of PEG5k-RB, PEG2k-FITC are the hydrodynamic diameters measured from dynamic light scattering. Sizes of TCTA and bromophenyl blue are measured from molecular structures. (A colour version of this figure can be viewed online.) 


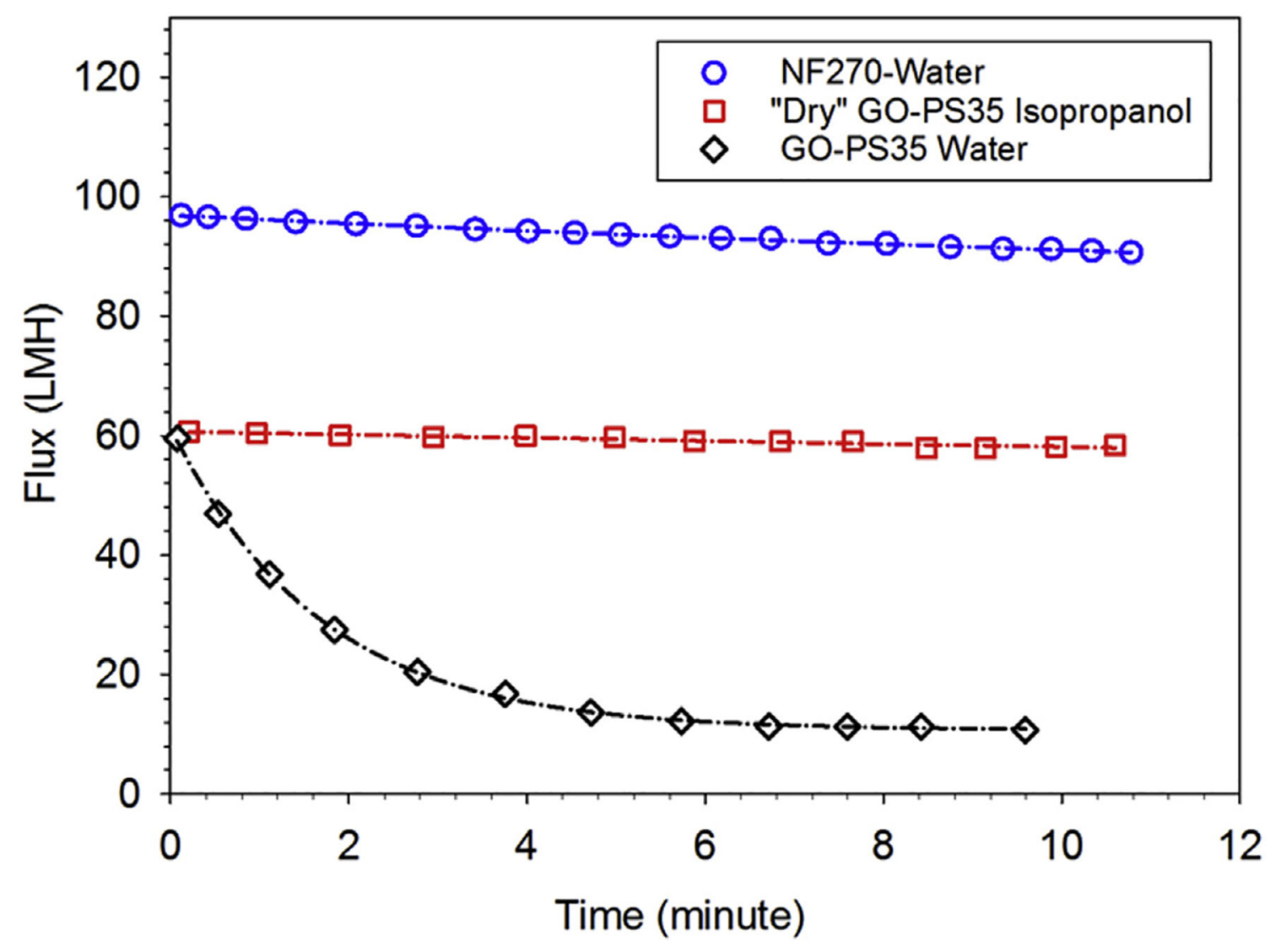

Fig. 10.

The permeate flux of a representative GO-PS35 and Dow NF270 membrane at 3.44 Bar. (A colour version of this figure can be viewed online.) 

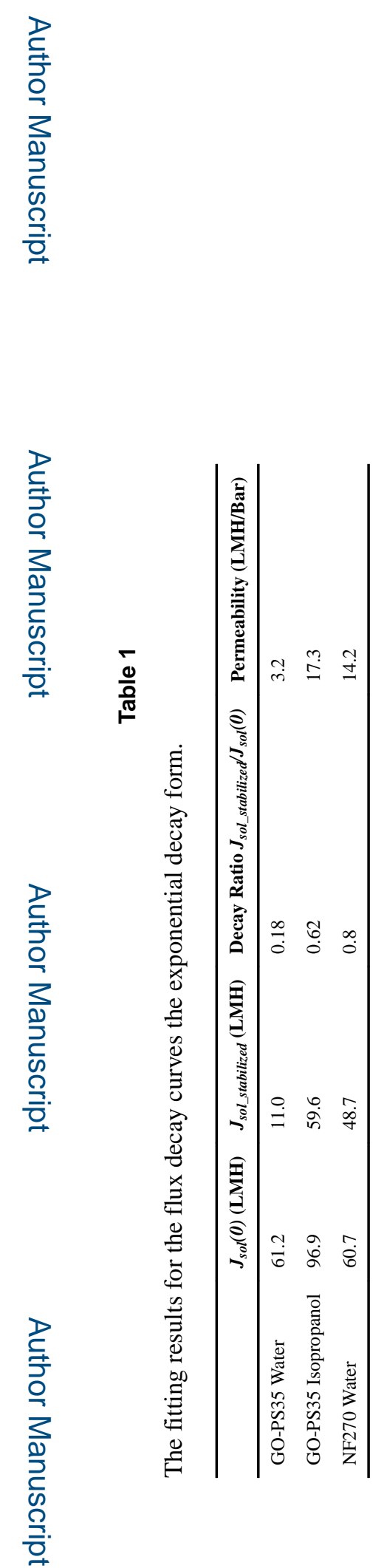

Carbon N Y. Author manuscript; available in PMC 2019 May 23. 